\title{
DESIGN APPLICATION AND ITS ECONOMIC ANALYSIS OF QUICK TEMPE TECHNOLOGY IN PAMULANG
}

\author{
Tabligh Permana1, Theofilus Christian' ${ }^{1}$, Stacia A. Fortunata ${ }^{1}$, Della Rahmawati ${ }^{1}$, Irvan S. \\ Kartawiria $^{2}$, Maria D.P.T. Gunawan-Puteri ${ }^{1 *}$ \\ ${ }^{1}$ Study Program of Food Technology, Faculty of Life Sciences and Technology, Swiss German University \\ ${ }^{2}$ Study Program of Chemical Engineering, Faculty of Life Sciences and Technology, Swiss German University \\ *Corresponding author: maria.gunawanputeri@sgu.ac.id
}

\begin{abstract}
Ipeh Tempe House in Pamulang was unable to fulfill their demand for more tempe production due to their limitation to expand the production using their own method. Quick Tempe technology is a Tempe production method with less production time than the common production method. Implementation of this method could increase production capacity without further infrastructure investment. Prior the implementation, the quick Tempe technology was adjusted with the current production method in Ipeh Tempe House. The scheduling models of GDL tempe production method in Ipeh tempe house were designed to increase the production capacity of Ipeh tempe house, and the economic analysis was also performed to see whether the schedules suggested was feasible to do in real life, by calculating the profits generated by the schedules, and all of them were more profitable than normal method. To conclude, the procedure can create more batches, while giving more profit, but validation for the procedure and calculation is still needed to be done, other thing such as back slopping sensory test is also need to be done.
\end{abstract}

Keywords : Tempe, Quick Tempe Method, Economical calculation, Design Application

\section{INTRODUCTION}

Indonesia has the largest tempeh production in the world it can produce up to 24 million tons per year and the profit from the industry can reach up to $\mathrm{Rp}$. 37 trillion per year [1].

The characteristic of small home industry that produced tempeh usually lives on highly dense population just like Kampung Kedaung in Pamulang is also one of the communities of tempeh artisan that live in a dense population.

Ipeh Tempe house is one of the Artisan that live In Kampung Kedaung, that have a high demand of tempeh and they need to increase their production capacity to full fill the demand. Increase production capacity usually involving production area

$$
\text { Teknologi Tepat Guna }
$$


expansion, however both are hardly aquired due to dense population

A new tempeh production method by using GDL (Glucono Delta-Lactone) that was developed to able to shorten the production time, so it can create a more productive time management for the workers [2]. GDL Production method can be used in Ipeh Tempeh House to increase their production capacity and full fill the demand.

Although quick tempeh method has a quicker production time compares to normal method, in order to increase the production capacity, a new system schedule that are capable to produce several batches of tempeh production on one day, the schedule will be designed with the characteristic of Ipeh Tempeh House in mind, which are time for selling, machine capacity and equipment, and the workforce.

The experiment will start with gathering information about Ipeh Tempeh House's characteristic which are time for selling, machine capacity and equipment, and the workforce, and the data obtained from information gathering will be used to adjust the GDL method into the Ipeh Tempeh house, hence creating a GDL method for Ipeh Tempeh House, the adjustments were the Starter amount, GDL addition method, and Backslopping Potential. When the adjustments were made, the schedule based on this was created to boost the production capacity without adding more equipment into the production room this new schedule will be based on the GDL production that was previously created for this step, and the suggested schedules were tested with. economic analysis for each production method that was suggested to see whether they are economically feasible to do in real production.

\section{METHOD}

The first stage of the experiment was designing a quick tempeh method design with the characteristic of Ipeh Tempeh house.

Production details, daily schedule of the production and the economical details of the production house was the characteristic on the Ipeh Tempeh House, and was obtained by interviewing the owner and visiting the place.

After the characteristic and production schedule was obtained, the GDL method will be implemented The second stage focuses on the scheduling of the new method so that the Tempeh house can produce tempeh for more than one time to increase the production without investing equipment, and the productivity was calculated and compared for onemonth production. There are several models that will be compared, model 0 , the old method,

The third and the final stage was to show the economical calculation based on the schedules that was suggested by the second stage, to prove that the schedules suggested can increase the profit without investing more money.

\section{RESULT AND DISCUSSION}

\section{Current Situation of Tempeh Production in Ipeh Tempeh House}

From the result of the observation and interview, the technology that the Ipeh Tempeh House have was rather modern, due to the addition of de-hulling machine, the steel tub had a build in faucet for water to be flushed after usage. The production condition can be seen on figure 1 . 

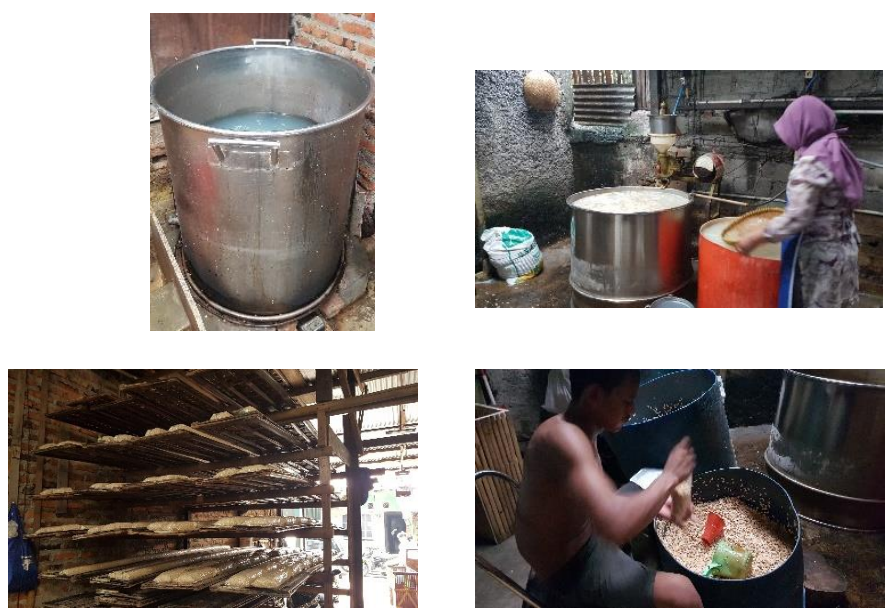

Figure 1. Boiling Tub, Dehulling Process, Yeast Mixing, and Incubation Process

The production method on the Ipeh Tempeh house was described with the flowchart on the figure 2, there were several steps that defined the Ipeh Tempeh House characteristics for the tempeh production, specifically on soaking, and boiling process.

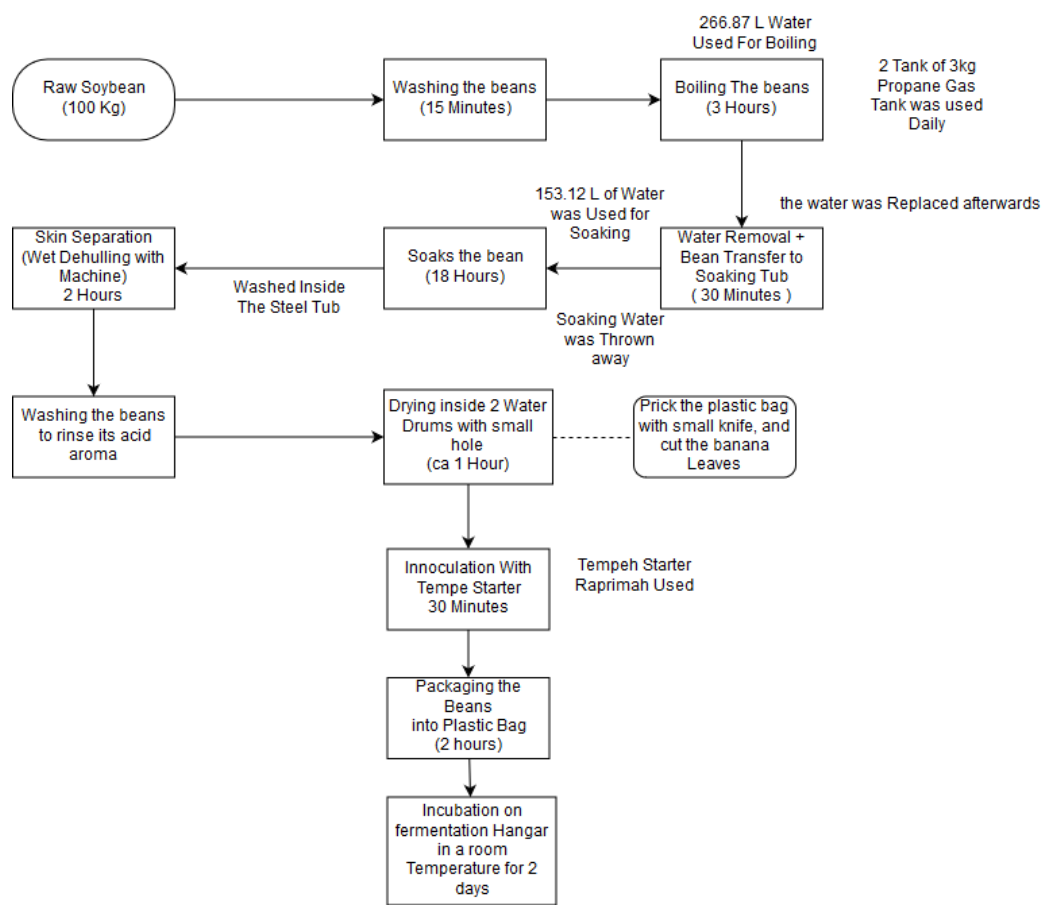

Figure 2. the Production Flow of Ipeh Tempeh House

The schedule was obtained from the interview and observations, the schedule from table 1 was based on the daily activity of the worker on Ipeh Tempeh House. The table depicts Tempeh House's worker who always came 
at $10 \mathrm{AM}$ and leave at $4 \mathrm{PM}$. The important characteristic of the production schedule was the time of selling the product and the soaking time that cannot be moved due to the selling time was always at 4:30 AM on the morning. Table 4 depicted the details of the tempeh production. It took 4 days to create one batch of tempeh daily. Meaning that there will be 27 batches of tempeh production in total. The production starts at 10 in the morning by cleaned and dehulled the beans that was previously soaked overnight and ends at 4 PM with packaging the tempeh from the same batch and soaked the next batch of beans for tomorrow.

Table 1. Daily Production Schedule

\begin{tabular}{|c|c|c|}
\hline \multirow{2}{*}{ TIME } & \multicolumn{2}{|c|}{ DAILY ROUTINE (1 Batch Per Day) } \\
\hline & Previous Batch & New Batch \\
\hline $01: 00$ & Soaking Beans & \multirow{3}{*}{ Incubation } \\
\hline 02:00 & Soaking Beans & \\
\hline 03:00 & Soaking Beans & \\
\hline 04:00 & Soaking Beans & Sell the Product \\
\hline 05:00 & Soaking Beans & \\
\hline 06:00 & Soaking Beans & \\
\hline $07: 00$ & Soaking Beans & \\
\hline 08:00 & Soaking Beans & \\
\hline 09:00 & Soaking Beans & \\
\hline $10: 00$ & Dehulling & \\
\hline 11:00 & Washing + Separation & \\
\hline $12: 00$ & Drying & \\
\hline $13: 00$ & Mixing With Tempe Starter & Washing the beans \\
\hline 14:00 & \multirow{2}{*}{ Packing the Beans } & \multirow{2}{*}{ Boiling Beans } \\
\hline 15:00 & & \\
\hline $16: 00$ & \multirow{9}{*}{ Incubation } & Soaking Beans \\
\hline $17: 00$ & & Soaking Beans \\
\hline $18: 00$ & & Soaking Beans \\
\hline 19:00 & & Soaking Beans \\
\hline $20: 00$ & & Soaking Beans \\
\hline $21: 00$ & & Soaking Beans \\
\hline $22: 00$ & & Soaking Beans \\
\hline $23: 00$ & & Soaking Beans \\
\hline 00:00 & & Soaking Beans \\
\hline
\end{tabular}

Table 1 details the daily production schedule based on Ipeh Tempeh House on Pamulang, Worker start the day at $10 \mathrm{AM}$ as indicated by the red mark at the table 1, and finish at around 4 PM. Soaking time as seen on table 1 was a long process, soaking started at noon and continue until the next day when the worker started working again at $10 \mathrm{AM}$, and the time were not flexible, due to the product selling time that cannot be changed due to the demand. Regular/normal tempeh production took 4 days for one batch of production. Total of 434 pieces of tempeh was 
produced daily at the Ipeh Tempeh House, to sum for one month, 13020 pieces of tempeh that were produced for 30 days of production.

The production flow then was reformed to fit with the GDL production method, with less washing and soaking time, but using the same equipment, only with an addition of GDL during soaking, to cut down production time.

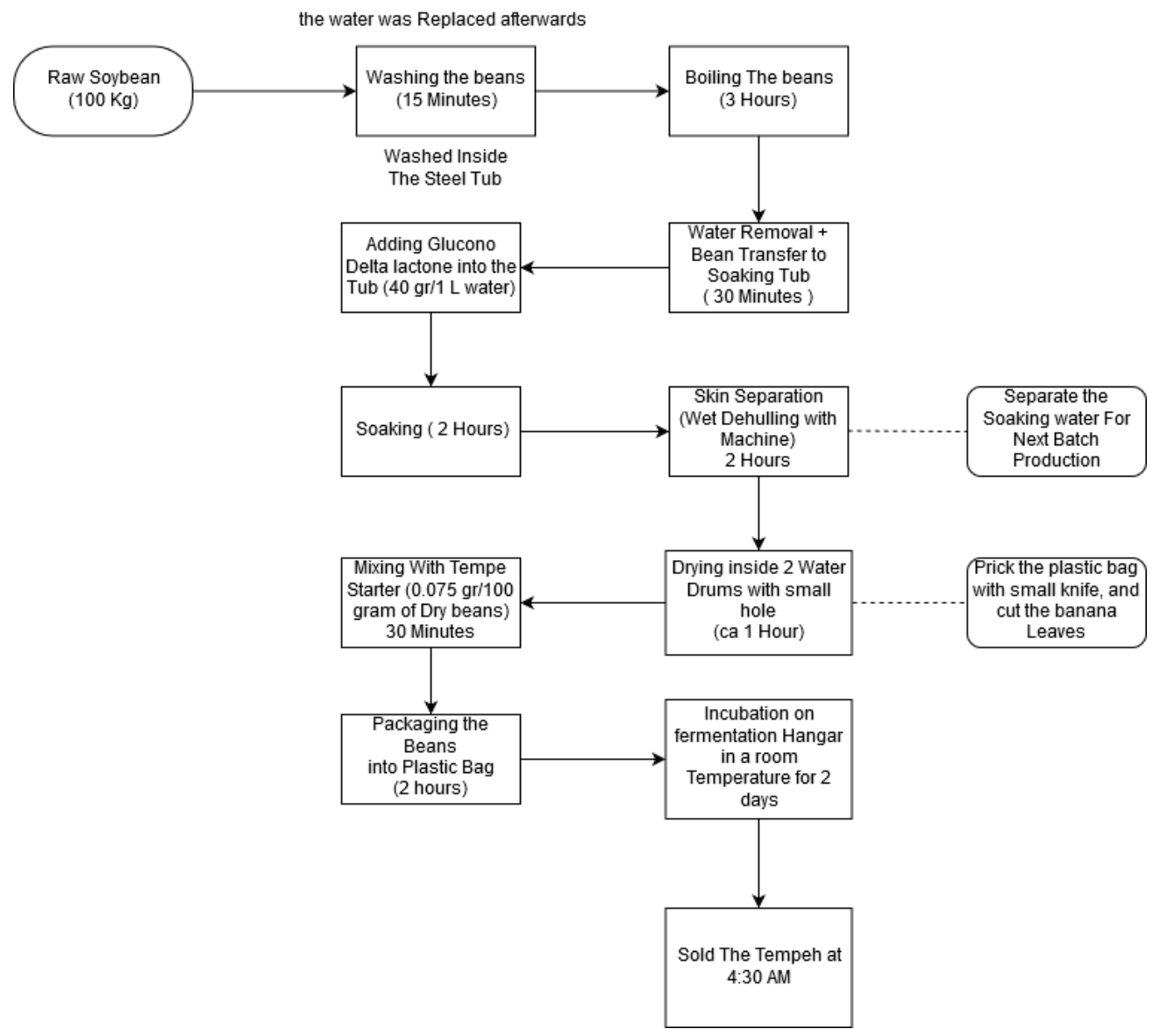

Figure 3 New GDL Designed Procedure Flowchart

the procedure that were depicted on the figure 3 was similar with the previous method, save for a few details, soaking process had mix the GDL within the water before the beans were added into the tub, and the soaking process duration was shortened from 18 hours into 2 hours.

This production flowchart will be the foundation for the next stage, which are designing a production schedule in Ipeh Tempeh House.

\section{Design of GDL Chemical Adition Application at Ipeh Tempeh House}

The production schedule was created based on what the employee's daily routine, by the interview that was done earlier. The data was manifested in a table form, where the schedule was written and compared. For this stage, several assumptions must be made to create an equal testing ground., assume that there are 30 days in one month instead of 31

$$
\text { Teknologi Tepat Guna }
$$


days, no production was made before the first day on the schedule, and there is also no production will be made if there are step that is need to be done past day 30. There will be 3 variant of schedule model that will be explained.

\section{Model 1 (2 Batch GDLAcidification Method)}

Model 1 composed of two GDL acidification method that was previously defined on stage 1 with several repetition to increase the production capacity within one day. the regular method cannot improve the productivity due to the tightness of the normal schedule that Ipeh Tempeh House had, the soaking was taking 18 hours as opposed the GDL soaking method, which was only 2 hours of soaking, the necessary equipment next then will be used again.

The potential schedule for the new production method, the first one being the new GDL method that was done twice a day, was possible due to time gap between each procedure, so the equipment such as the boiler, the soaking tank can be used twice each day.

GDL production schedule need 1 day less to complete the production, can create more batches than the normal production schedule, and the new GDL production can be done two times a day, to increase the productivity since the worker started earlier on the day which at $7 \mathrm{AM}$, and finish at $7 \mathrm{PM}$, which were longer compared to the normal method.

Table 2 detailed the model schedule that the worker will as the daily basis, with two schedules per day, the first batch began at $7 \mathrm{AM}$ and the second batch begun $10 \mathrm{AM}$, when the first batch undergoes soaking. The rest was similar with the last procedure until it was ready to be sold. 
Table 2. Model 1 (2 GDL method Schedule)

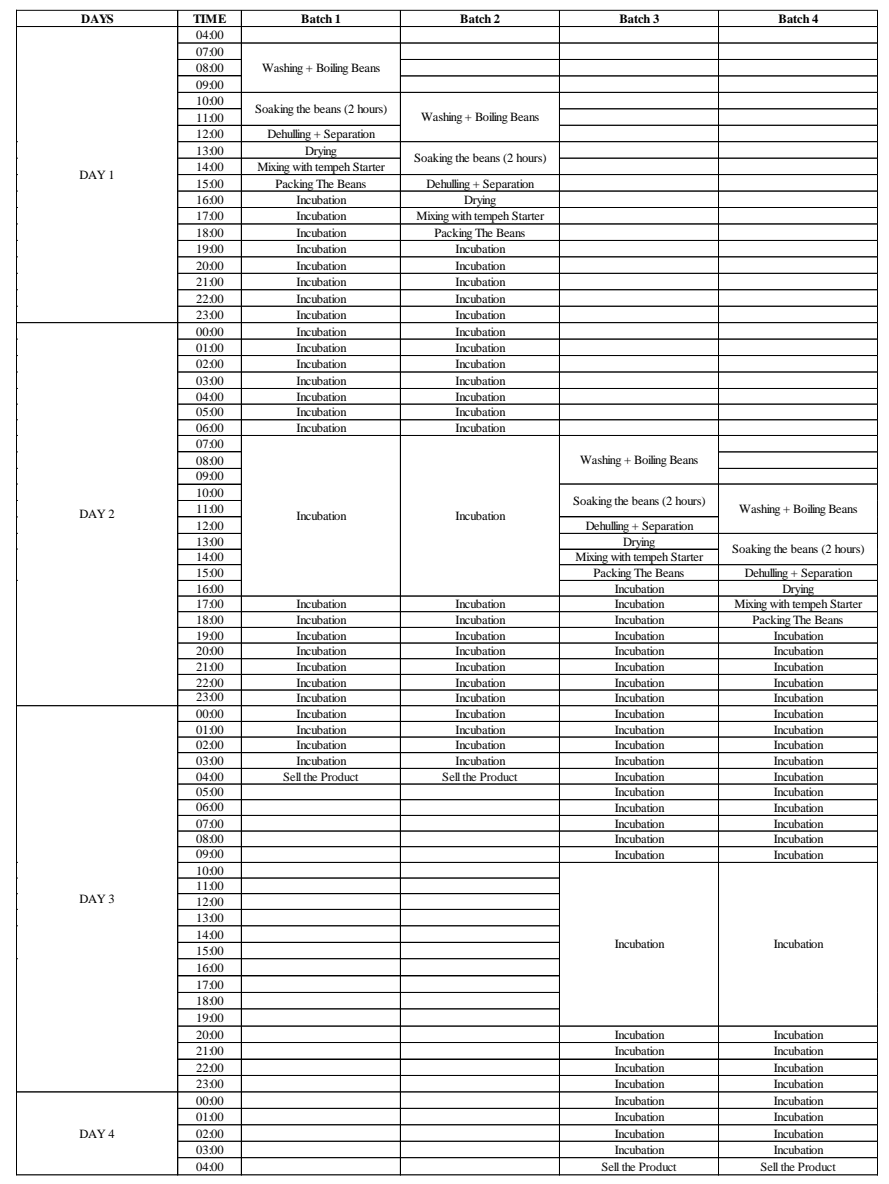

Within the first month, the production had increased since there were two batches for 1 day as opposed to one batch per day, naturally the productivity was also increased since there are many more that worker need to be done. The schedule changes the worker working schedule from $10 \mathrm{AM}-4 \mathrm{PM}$ to $7 \mathrm{AM}-7 \mathrm{PM}$, the change happened due to the selling time is still at 4:30 AM, the new method had to adjust the time for incubation and the tempeh condition when it was delivered, and the production was also altered to prevent the and no downtime on the equipment since it was being used multiple time during the day, and finally, worker's salary was also adjusted on the later stage to compensate the extra worktime for the new model.

There were 60 batches of production as opposed to the normal schedule, there are pieces of tempeh that can be sold for 30 days ( 1 month) of the implementation of table 2 .

\section{Model 2 (2 GDL Method + 1 Natural Method)}

Model 2, combined both of the normal procedure with model 1 procedure, hence the production becomes three batches per day, which was possible to do. To leave the soaking for normal production elsewhere without disrupt the flow of the GDL production, just with additional tub that Ipeh Tempeh House had.

Due to combining the previous method, even more tempeh can be sold per day and this schedule 
can be applied if the demand is super high compare to the previous schedule, since it can produce up to 3 batches per day. On first month of the production, it can create up to 39060 pieces of tempeh for 30 days
(1 month), which was really huge when compares to the original procedure. And the detail of the procedure will be presented on table 3 .

Table 3. Model 2 (2 GDL Schedule + 1 natural acidification Schedule)

\begin{tabular}{|c|c|c|c|c|}
\hline \multirow{2}{*}{ TIME } & \multicolumn{4}{|c|}{ DAILY PRODUCTION } \\
\hline & GDL BATCH & GDL BATCH 2 & Normal Batch 1 & Normal Batch 2 \\
\hline 00:00 & & & Soaking Beans & \multirow{4}{*}{ Incubation } \\
\hline 01:00 & & & Soaking Beans & \\
\hline 02:00 & & & Soaking Beans & \\
\hline 03:00 & & & Soaking Beans & \\
\hline 04:00 & Sell the Product & Sell the Product & Soaking Beans & Sell the Product \\
\hline 05:00 & & & Soaking Beans & \\
\hline 06:00 & & & Soaking Beans & \\
\hline 07:00 & \multirow{3}{*}{ Washing + Boiling Beans } & & Soaking Beans & \\
\hline $08: 00$ & & & Soaking Beans & \\
\hline 09:00 & & & Soaking Beans & \\
\hline $10: 00$ & \multirow{2}{*}{ Soaking the beans ( 2 hours) } & \multirow{3}{*}{ Washing + Boiling Beans } & Dehulling & \\
\hline $11: 00$ & & & Washing + Separation & \\
\hline $12: 00$ & Dehulling + Separation & & Drying & \\
\hline 13:00 & Drying & \multirow{2}{*}{ Soaking the beans ( 2 hours) } & Mixing With Tempe Starter & Washing the beans \\
\hline $14: 00$ & Mixing with tempeh Starter & & \multirow{2}{*}{ Packing the Beans } & \multirow{2}{*}{ Boiling Beans } \\
\hline $15: 00$ & Packing The Beans & Dehulling + Separation & & \\
\hline $16: 00$ & \multirow{9}{*}{ Incubation } & Drying & \multirow{9}{*}{ Incubation } & Soaking Beans \\
\hline $17: 00$ & & Mixing with tempeh Starter & & Soaking Beans \\
\hline 18:00 & & Packing The Beans & & Soaking Beans \\
\hline 19:00 & & Incubation & & Soaking Beans \\
\hline $20: 00$ & & & & Soaking Beans \\
\hline 21:00 & & & & Soaking Beans \\
\hline 22:00 & & & & Soaking Beans \\
\hline $23: 00$ & & & & Soaking Beans \\
\hline 00:00 & & & & Soaking Beans \\
\hline
\end{tabular}

Table 3 displayed the production schedule of model 2. Similar to model 1, the work started at 07 AM, and finish at $7 \mathrm{PM}$, with 3 batches of production to be done per day, started with washing and boiling for GDL production batch, at $10 \mathrm{AM}$, the washing for the next batch of GDL production started until all the procedure were finished at 7 AM similar to the model 1 and the difference at model 2 was the additional batch from model 0 . The flow of the GDL batches production was not interrupted within each other since there was no clashing of usage of equipment, to eased the worker, and production increased.

The normal production batch started at $1 \mathrm{PM}$ on the afternoon, the rest of the normal production will be continued the next day during the soaking. Every day, tempeh created will be sold at 4 AM daily. The important soaking process for normal procedure was around 1 day, and the timing between dehulling for normal method and soaking method of GDL batch 1 was tight at $10 \mathrm{AM}$, the beans must have been removed and cleaned in small period of time, so that the schedule did not crashed with each other.

Another important part was when the methods started to conjunction with one another, the timing of the production for each batch had to be precise and punctual for the worker to be finished at 7 PM. To mitigate the issues, additional worker can be hired in order to save time.

The model schedule can be used if the demand was big and model 1 cannot handle the production capacity that was demanded by the consumer.

Teknologi Tepat Guna 


\section{Model 3 (1 GDL Method + 1 Natural Method)}

Another schedule model was suggested, the new model was based on modification of Model 2 of 3 batches of tempeh production schedule by removed one GDL schedule from the model, resulted on a more manageable schedule, with less worktime for the worker, lessening the chance of unnecessary stress caused by overworking, the modified model was called model 3 , and the schedule can be seen on the table 4.

Table 4 Model 3 Schedule (1 Normal Method and Sync Method)

\begin{tabular}{|c|c|c|c|}
\hline \multirow{2}{*}{ TIME } & \multicolumn{3}{|c|}{ DAILY PRODUCTION } \\
\hline & GDL BATCH & Normal Batch 1 & Normal Batch 2 \\
\hline $00: 00$ & & Soaking Beans & \multirow{4}{*}{ Incubation } \\
\hline 01:00 & & Soaking Beans & \\
\hline 02:00 & & Soaking Beans & \\
\hline 03:00 & & Soaking Beans & \\
\hline 04:00 & Sell the Product & Soaking Beans & Sell the Product \\
\hline $05: 00$ & & Soaking Beans & \\
\hline $06: 00$ & & Soaking Beans & \\
\hline $07: 00$ & \multirow{3}{*}{ Washing + Boiling Beans } & Soaking Beans & \\
\hline 08:00 & & Soaking Beans & \\
\hline 09:00 & & Soaking Beans & \\
\hline $10: 00$ & \multirow{2}{*}{ Soaking the beans ( 2 hours) } & Dehulling & \\
\hline $11: 00$ & & Washing + Separation & \\
\hline $12: 00$ & Dehulling + Separation & Drying & \\
\hline $13: 00$ & Drying & Mixing With Tempe Starter & Washing the beans \\
\hline $14: 00$ & Mixing with tempeh Starter & \multirow{2}{*}{ Packing the Beans } & \multirow{2}{*}{ Boiling Beans } \\
\hline $15: 00$ & Packing The Beans & & \\
\hline $16: 00$ & \multirow{9}{*}{ Incubation } & \multirow{9}{*}{ Incubation } & Soaking Beans \\
\hline $17: 00$ & & & Soaking Beans \\
\hline $18: 00$ & & & Soaking Beans \\
\hline 19:00 & & & Soaking Beans \\
\hline $20: 00$ & & & Soaking Beans \\
\hline $21: 00$ & & & Soaking Beans \\
\hline $22: 00$ & & & Soaking Beans \\
\hline $23: 00$ & & & Soaking Beans \\
\hline 00:00 & & & Soaking Beans \\
\hline
\end{tabular}

The table 4 displayed a reduced work duration that prevent the risk of overworking, only from 7 AM to 4 PM with two batch of production daily, as opposed of model 2's 3 batches of production per day. With the schedule model on table 11, there are 60 batches of tempeh production on the 30 days (1 Month)

After every model that were possible were created, the next stage was to compares them with a production capacity analysis.

\section{Potential Economic Improvement of GDL Chemical Acidification}

The goal of stage 3 was to show that, the schedule that was suggested from the stage 2 of the experiment, was feasible to be used in the future, and to show that not only the productivity of the worker can be increased, but also the profit of each schedule for 1 month full of operation, so it can be calculated easily. But before calculating the profit, the productivity of each model must be tested

The potential for the new method was astounding since it can double or triple the batch of the tempeh at the expense worker's increased salary since 2-day schedule will be merged into one giant schedule, and it will affect the worker's salary and time 
management, hence further discussion with the Artisan's and the employee must be done.

Implication was used for this analysis, the weight of the tempeh was used to calculate the productivity, and the weight was 500 gram of tempeh each.
The analysis of Productivity is done by subtracting the Weight of tempeh for each model for 1 month and was compared on table 5 .

Table 5. Production Capacity Analysis

\begin{tabular}{|l|c|c|c|c|}
\hline Model & Tempeh Production Schedule & Production Capacity Increase (\%) & Tempeh Pieces Sold for 30 days (1 Month) & Tempeh Sold's Weight for 1 Month (Kg) \\
\hline Model 0 & 1 Batch Natural Method & Normal & 13020 & 6510000 \\
\hline Model 1 & 2 Batches of GDL Method & $100 \%$ & 26040 & 13020000 \\
\hline Model 2 & 2 Batches of GDL Method + 1 Batch Natural & $200 \%$ & 39060 & \\
\hline Model 3 & 1 Batch of GDL Method + 1 Batch Natural & $100 \%$ & 26040 & 19530000 \\
\hline
\end{tabular}

Model 0 means the natural method, model 1 is the 2 times GDL method, Model 2 is the Model $1+0$, Model 3 is 1 GDL production + 1 normal production method

Table 5 displayed that between the three models that were constructed, the one who had the biggest productivity increases was model 2 which had increased productivity for up to $200 \%$ compares to normal method/model 0 , followed by model 1 which was increase from the model 0 , and model 3 was similar to the model 1 , increased the productivity from the model 0 to $100 \%$ more productivity.

Figure 4 was created to show that the model 2 had increased the most compared to another model.

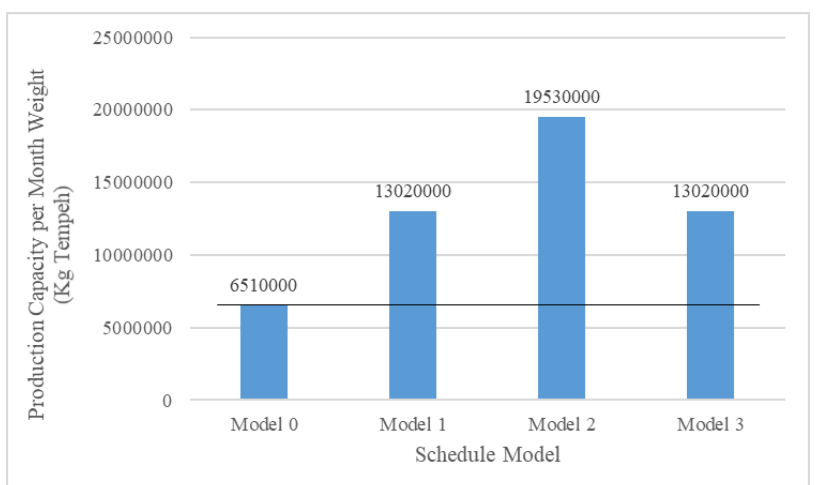

Figure 4. Productivity of Scheduling Model 0, 1, 2, and 3 for 1 Month of Productions.

Figure 4 showed that all of three model can be concluded to be able to increase productivity, there were another step that is need to be done to show if the model can be applicable on the real situation, by calculating the profit for each model to compare, that the profit can increase for the models, since it is possible that, even the productivity increase, the profit may not, so proper analysis will be done in the next stage.

The formula for calculating profit was the revenue substracted by the total production cost.

$$
\text { Profit = Revenue }- \text { Total Production Cost (1) }
$$

One of the variables that was used for the economical calculation was the price for each of the raw material used for the production, and the price will be adjusted depends on each model since the required raw materials, wages, and electricity and water usage can be different for each model, due to different number of production batch. The formula was used for all the model for comparison.

\section{Potential Revenue Improvement}

The revenue was total sale for one day multiplied by 30 that stands for 30 days of production.

$$
\text { Revenue }=\text { Total Sales } 1 \text { Day } * 30
$$

\section{Total Tempeh Sales}

The total sales for one day was the tempeh price multiplied by the amount of tempeh sold for 1 batch, that was displayed on table 6 . The table was based on the model 0 (current method) daily production, a 100 $\mathrm{kg}$ of soybeans can be created into 434 pieces of tempeh daily. 
Table 6. Daily Tempeh Production Pricing and Pieces

\begin{tabular}{|c|c|c|c|}
\hline \multirow{2}{*}{ Tempeh types } & Produce Daily & Price/piece & Total \\
\hline & (Block) & (Rp) & (Price) Rupiah \\
\hline 500 gram block & 127 & Rp3.500 & Rp444.500 \\
\hline 1 kg Block & 86 & Rp7.000 & Rp602.000 \\
\hline \multirow{2}{*}{$\begin{array}{c}\text { Long Barrel, cut } \\
\text { in } 13 \text { pieces } / 500 \\
\text { gram each }\end{array}$} & \multirow{2}{*}{169} & Rp3.500 & \multirow{2}{*}{ Rp591.500 } \\
\hline & & (Per Pieces) & \\
\hline \multirow{2}{*}{$\begin{array}{c}\text { Long Barrel, cut } \\
\text { in } 13 \text { pieces }\end{array}$} & \multirow{2}{*}{52} & Rp3.500 & \multirow{2}{*}{ Rp182.000 } \\
\hline & & (Per Pieces) & \\
\hline Total & 434 & & Rp1.820.000 \\
\hline
\end{tabular}

The tempeh Types and price data were obtained by interview with the Ipeh Tempeh House Owner, table 6 was the amount of tempeh and pricing of the tempeh of model 0 that would be used for model 1, 2, and 3, with the assumption that table 6 was the amount of tempeh that can be produced for one batch.

\section{Total Tempeh sales for each model}

With assumption that the daily production was always the same even with multiple batches of tempeh, the calculation was only needed to be multiplied by the number of productions per day.

The total sales of tempeh were calculated with the formula number 3

$$
\begin{gathered}
\text { Total Sales } 1 \text { day }= \\
\sum \text { (Amount of Tempeh types that can be produced daily } x \text { Price of said Tempeh Types) }
\end{gathered}
$$

By multiplying the sales number with the production batches for each model, since the implication used in the beginning was the tempeh, no matter how many, was always sold out. The formula (2) was used to calculate the revenue / sales of each model.

The total sales for one day then was multiplied by 30 that stands for 30 days in one month.

Table 7. Model Tempeh Sales for 1 Month

\begin{tabular}{|c|c|c|c|}
\hline Number & Model & Sale 1 for Day & Sales for 30 days \\
\hline 1 & Model 0 (Normal) & $\mathrm{Rp} 1.820 .000$ & $\mathrm{Rp} 54.600 .000$ \\
\hline 2 & Model 1 (GDL 2 $\mathrm{x}$ ) & $\mathrm{Rp} 3.624 .000$ & $\mathrm{Rp} 108.720 .000$ \\
\hline 3 & Model 2 (GDL 2x + Normal) & $\mathrm{Rp} 5.436 .000$ & $\mathrm{Rp} 163.320 .000$ \\
\hline 4 & Model 3 (GDL + Normal) & $\mathrm{Rp} 3.624 .000$ & $\mathrm{Rp} 109.200 .000$ \\
\hline
\end{tabular}

Table 7 indicated the revenue that the Tempeh house have for 1 month. To obtained the profit, total production cost was also needed to be calculated, the formula for the production cost or variable cost was the cost of goods/ raw materials addition of cost of wages for each model, with addition of the gas, water, and electricity cost.

\section{Expected Rise of Total Production Cost}

Other important component of profit calculation was the total production cost of the tempeh model, to calculate the production cost, variable cost and production expenses cost was needed.

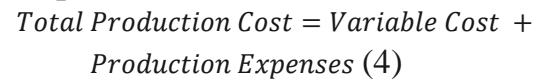

\section{Variable Cost}

Variable Cost $=($ Soybean Usage Cost + Tempeh Starter Usage Cost + GDl Usage Cost + Plastic Usage Cost (5)

The cost of goods / the material cost was divided into the raw soybean cost, tempeh starter usage, the GDL usage, the amount of plastic usage. The raw material cost per batch and brand name was displayed on table 8 . 
Table 8. Material Used and Price Cost for the Economical Calculations

\begin{tabular}{|c|c|c|c|}
\hline Number & \multicolumn{2}{|c|}{ Production cost } & Cost 1 Production \\
\hline 1 & Raw Soybean & 100 Kilogram & Rp750.000 \\
\hline 2 & Tempeh Starter & 250 gram/ 500 gram & Rp7.500 \\
\hline 3 & Electricity & 70 Kilowatt (1352 Rp/KwH & Rp500.240 \\
\hline 4 & \multirow{2}{*}{ Water } & Arround $450 \mathrm{~L}$ & Rp135.000 \\
\hline 5 & & 420 Litre(300 Rp/Litre) & Rp126.000 \\
\hline \multirow[t]{2}{*}{6} & \multirow{2}{*}{ Plastic (3 sizes) } & 434 plastic & \multirow{2}{*}{ Rp34.720 } \\
\hline & & Rp80/pieces & \\
\hline 7 & Gas & $3 \mathrm{~kg}$ (30k / tabung) & Rp30.000 \\
\hline 8 & Worker & Rp18.333 & Rp109.998 \\
\hline 9 & Hull & $10 \mathrm{Kg}$ & Rp3.000 \\
\hline
\end{tabular}

The material that will be used was displayed at table 8, the soybean, tempeh starter, GDL, gas tanks, and all the plastic that was used for one production was displayed. The calculation of the profit will be based on 30 days of production, the formula to calculated the profit needed the number of the raw material. The formula 5 can be applied to other models as well.

Water and electricity were a part of the operating expenses, including the wage of the worker, which was also part of the variable cost.

\section{Comparison of Potential Revenue, Cost and Profit}

The Total Production Cost after each variable of the for total production cost was done with the table 9 that showed the total production cost of each model schedule with the variables from the soybean usage per month to the wage of the worker in Ipeh Tempeh House.

Table 9. Total Production Cost of Each Model Schedule

\begin{tabular}{|c|c|c|c|c|c|c|c|c|c|}
\hline \multirow{2}{*}{ Cost Unit } & \multicolumn{5}{|c|}{ Usage } & \multicolumn{4}{|c|}{ Cost / Month } \\
\hline & Unit & Model 0 & Model 1 & Model 2 & Model 3 & Model 0 & Model 1 & Model 2 & Model 3 \\
\hline $\begin{array}{c}\text { Raw } \\
\text { Soybean }\end{array}$ & $\mathrm{Kg}$ & 3000 & 6000 & 9000 & 6000 & Rp22.500.000 & Rp45.000.000 & Rp67.500.000 & Rp45.000.000 \\
\hline GDL & gram & 0 & 122496 & 122496 & 61248 & $\mathrm{Rp} 0$ & Rp2.817.408 & Rp2.817.408 & Rp1.408.704 \\
\hline $\begin{array}{c}\text { Tempeh } \\
\text { Starter }\end{array}$ & gram & 3000 & 4500 & 7500 & 5250 & Rp18.000 & Rp27.000 & Rp45.000 & Rp31.500 \\
\hline \begin{tabular}{|c|} 
Plastic \\
Packaging \\
\end{tabular} & piece & 13020 & 26040 & 39060 & 26040 & Rp1.041.600 & Rp2.083.200 & Rp3.124.800 & Rp2.083.200 \\
\hline Gas & tank & 30 & 60 & 90 & 60 & Rp1.800.000 & Rp3.600.000 & Rp5.400.000 & Rp3.600.000 \\
\hline Water & Litre & 16080 & 20949,6 & 41049,3 & 30574,5 & Free & Free & Free & Free \\
\hline Electricity & $\mathrm{kWh}$ & 5024,925 & 5237,4 & 10262,325 & 7643,625 & Rp6.801.202 & Rp7.095.972 & Rp13.897.174 & Rp10.349.188 \\
\hline Wage & person & 1 & 1 & 2 & 1 & Rp3.300.000 & Rp6.599.880 & Rp13.199.760 & Rp4.949.910 \\
\hline \multicolumn{6}{|c|}{ TOTAL COST } & Rp34.560.802 & Rp65.423.460 & Rp 103.284.142 & Rp65.622.502 \\
\hline
\end{tabular}

Usage and Cost were Calculated Monthly 
The water was freely flowing from the well near the production, so the price was free and the electricity price accounted the pump usage. The wage of the worker was different in each model, since it depended on the workhour of each schedule model, and in model 2 calculation, there were two workers suggested in order to balance the work that was needed to be done in one day.

The unit For GDL was called a replacement for each usage due to backslopping was implemented within the production, the amount of GDL was always the same, but the difference was on the replacement time for models that used GDL method, more GDL batches that was produced, more GDL solution replacement was needed.

Table 10. Profit Comparison Between Each Model for 1 Month of Production

\begin{tabular}{|c|c|c|c|}
\hline Schedule Models & PRODUCTION COST & Revenue & Profit \\
\hline Model 0 & Rp34.560.802 & Rp54.600.000 & Rp20.039.198 \\
\hline Model 1 & Rp65.423.460 & Rp108.720.000 & Rp43.296.540 \\
\hline Model 2 & Rp103.284.142 & Rp163.320.000 & Rp60.035.858 \\
\hline Model 3 & Rp65.622.502 & Rp108.720.000 & Rp43.097.498 \\
\hline
\end{tabular}

Table 10 showed the profit for each model were Increased compares to the Model 0, with the highest is with model 2, which has 3 batches per day, even though the cost increased, but the profit also increased. Figure 6 shows the profit for each model schedule was better than the model 0 or standard model.

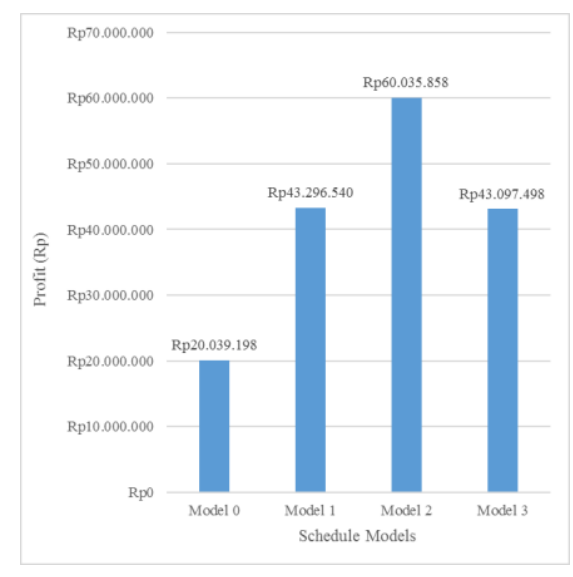

Figure 5. Profit Comparison Chart Between Each Model for 1 Month of Production

This conclude that every model that were suggested can be used in the Tempeh House, so they can adjust their production model according to the demand that they may had in the future, although there are several assumptions that must be eliminated.

\section{CONCLUSION}

Based on the potential economic calculation on the profit the new GDL acidification method, all the model schedule suggested can potentially increase the production capacity and the revenue without any addition in equipment, and space on the production line. Even though the production cost is inevitably going to increase due to the addition of GDL and multiple tempeh production can be happened during single day, but the profit that the suggested model can be potentially higher than the natural acidification method.

But since only the hypothetical and potential calculation that has been done, the real calculation and the GDL application treatment have not yet been done and the real result have yet to be seen.

\section{AKNOWLEDGEMENT}

Swiss German University Central Community Service Fund for Funding this research.

\section{REFERENCE}

[1] Badan Standarisasi Nasional, 2012 Booklet of Tempeh. Available at: http://www.bsn.go.id/uploads/download/Booklet_tempeprinted21.pdf

[2] Wijaya, H, Gunawan, M, Kusumanigrum, H, \& Nurtama, B 2014, proses pembuatan tempe melalui pengasaman kimiawi dengan menggunakan glukono-delta-laktone (gdl), 000035720 . 